I thank my friend for the advice contained in his classically-concluding letter. I see that I must in future more frequently turn the stilus if I wish to avoid the criticism of so severe a Metius Tarpa.

$$
\begin{aligned}
& \text { I am, Sir, } \\
& \text { Your obedient servant, }
\end{aligned}
$$

\author{
Alliance Assurance Office, $\quad$ H. W. PORTER. \\ 2nd Sept., 1861.
}

\title{
ON THE RECENT IMPUTATIONS MADE AS TO MR. GOMPERTZ'S ACCURACY.
}

\section{To the Editor of the Assurance Magazine.}

SiR,- - The lengthy paper by Mr. Edmonds, which appeared in the last Number of the Assurance Magazine, renders it necessary that I should recur to a subject, which I should not again have approached if I had consulted my own inclination. In that paper, Mr. Edmonds has taken particular pains to answer some of my criticisms; and it will probably be correct to assume, that but for those criticisms this last paper of his would never have been written. Nevertheless my name is not once mentioned in that paper, but I am designated "the new advocate of Mr. Gompertz." If my remarks had been made anonymously, this would have been a perfectly natural and appropriate course for Mr. Edmonds to adopt; but under existing circumstances, I am unable to perceive what advantage the course adopted by him, has over the more obvious one of naming the person whose arguments he undertakes to meet. As there may, however, perhaps be some hidden merit in this course, to be discovered only upon trial, it may be worth while to try the effect of adopting some similar circumlocution. Thus I hope that in speaking of the "plagiarist of Mr. Gompertz," I shall be as well understood by your readers, as if I mentioned a name with which recent controversy will have rendered them familiar.

I have carefully read the paper by the plagiarist of Mr. Gompertz, and examined thoroughly all the arguments made use of by bim in his defence; and I find that in one particular only, to be mentioned directly, is there any necessity to alter what I had previously written. Thus I might have rested content with making the single necessary correction, and referring the reader back to my unanswered arguments, without opening any fresh ground; and I should certainly have done so, had not the plagiarist of Mr. Gompertz taken the opportunity of throwing several fresh imputations upon the accuracy of Mr. Gompertz, equally unfounded with the former ones. In consequence of his having pursued this course, it becomes desirable to examine in detail both these new imputations and the answers to my former criticisms.

First, as to the point on which my former remarks require modification. I stated that I had come to the conclusion that the plagiarist of Mr. Gompertz had been "under a misconception as to the real nature of the process of integration." From his recent explanation (pp. 339, 340) I gather that he uses the phrase "process of integration" as equivalent to "solution" of the differential equation, and not, as I had supposed, in the more limited application to the step in which both sides of the equation are integratedthis step being (3) in my demonstration on p. 289. I therefore withdraw the particular remark as as to the "misconception" (p. 291); but in doing 
this, I wish it to be particularly understood that I do not modify in the least the other remarks contained in the same paragraph. On the contrary, I find the conclusions I had arrived at singularly confirmed, and the observed phenomena at the same time explained, by a statement made by the plagiarist of Mr. Gompertz on p. 334, that he had omitted to read mathematics during the whole of the second year of his academic course. Those who are acquainted with the nature of the studies pursued at Cambridge, will at once admit how impossible it is for a student who has neglected to "read" during the second year of his course, to take up with any benefit or prospect of success, the subjects belonging to the third year. Thus I can now readily account for what seemed a very curious circumstance previously, that the plagiarist of $\mathrm{Mr}$. Gompertz, having formed the differential equation $d y=-y a p^{x} d x$, should have been unable to integrate it, as he frankly confesses (p. 178), although the process was " simple and well known."

Before proceeding to examine the new ground taken by the plagiarist of Mr. Gompertz, it will be convenient to reyiew the answers he has put forward to my former remarks.

First, with regard to the constant $d$. I remarked that $d$ is "an essential part of the formula, and as such is employed by Mr. Edmonds himself." To this he replies '(p. 340), "There is not the remotest approach to truth in this statement." It would be difficult to invent a more precise form of contradiction than is here employed. Let us see how far it is justified by facts. If the reader will turn to p. 336 , he will find this identical letter $d$ employed by Mr. Edmonds in the equation

$$
\log \cdot y=\log \cdot d-\frac{a p^{x}}{\log \cdot p}
$$

Again, if he will turn to p. 88 , he will find the same quantity introduced, but there denoted by the letter $g$. How can the plagiarist of Mr. Gompertz say after this that he has not employed the quantity $d^{2}$ If $d$ were really "superfluous" and " useless," it should be used neither in the process of solution of the differential equation, nor yet in the formula for $\mathrm{L}_{x}$. It should therefore be omitted, and we should have simply $\mathrm{L}_{x}=g^{q^{x}}$. But the plagiarist of Mr. Gompertz must admit this is not accurate, and that it would be impossible to deduce therefrom his favourite formula $10^{\frac{k^{2} \alpha}{p}(1-p x)}$ It makes no difference to the argument that the plagiarist of $\mathrm{Mr}$. Gompertz has assigned a particular value to $d$ in his formula. If he had not employed $d$ at all, his formula would have been $10^{-\frac{k^{2} \alpha}{\lambda p} \cdot p^{x}}$, instead of that which he has actually employed. It should be noticed that this formula, which must be acknowledged by the plagiarist of Mr. Gompertz to be "defective," is very little more so, if at all, than his own, $10^{\frac{k^{2} \alpha}{\lambda p}\left(1-p^{x}\right)}$. Neither gives the actual number of persons living at the age $x$. The former requires to be multiplied by the constant factor $\mathrm{L}_{0} \cdot 10^{\frac{k^{2} a}{\lambda p}}$; and the latter by the constant factor $\mathrm{L}_{0}$. On the contrary, Mr. Gompertz's formula, $d g^{q^{x}}$, does give the actual number living at the age $x$. It may be allowed to a person entertaining the views expressed by the plagiarist of Mr. Gompertz, to call

voL. $\mathbf{x}$. 
this formula " defective," as not being put in the form which appears to him the most complete and convenient; but there can be no possible pretext for terming it "erroneous," as is done on p. 336. I have thus shown that the formula is incomplete without $d$, and that if the plagiarist of $\mathrm{Mr}$. Gompertz had not made use of $d$, his formula would have had a very different form. Therefore, I repeat, $d$ is not superfluous, and is employed by Mr. Edmonds himself; and I leave it to those who are competent, to decide which of us is correct. Before leaving this point, it is worth while to notice the amusing ineonsistency of the plagiarist of $\mathrm{Mr}$. Gompertz, who (p. 181) says that the process of integration is rendered obscure and ambiguous by the aid of the superfluous and useless indeterminate constant $d$, and yet himself introduces this very constant as I have shown.

Nor, secondly, is $d$ "indeterminate." It would appear (v. p. 338) that the plagiarist of Mr. Gompertz has purposely employed this word in a sense different to that to which it is usually limited. To this course there is only one objection, viz, that a writer pursuing it is certain to be misunderstood. This may be obviated by a process which tradition affirms to have been employed in the "schools" at Cambridge. A student under examination made the error of writing 4 instead of 3 throughout a mathematical demonstration. Arrived at the conclnsion, he discovered his error; but being pressed for time, instead of correcting the demonstration throughout, he appended a note-"N.B. Throughout the above demonstration the symbol (4) denotes three units." So, the plagiarist of $\mathrm{Mr}$. Gompertz should say, "By the word indeterminate, I denote, not, as is commonly understood, that of which the value cannot be determined, but"-something quite different. Such a course may be thought by some persons to have its recommendations; and the meaning of the writer might be ascertained by the use of sufficient care. But the use of a word without comment in a sense different from that attached to it by all other persons, is wholly unjustifiable!

The plagiarist of Mr. Gompertz argues (p. 337) that $d$ is rightly called indeterminate in the usual sense, because (he asserts) "Mr. Gompertz and his two advocates" have been unable to determine its value. If this were true, still he forgets that since he has succeeded in getting the value of $d$, it can no longer be called indeterminate. But as to the question of fact, he would have found, if he had read two lines further (p. 291), that Mr. Gompertz's "new advocate" had succeeded in determining the value of $d !$ He would have found the equation $\mathrm{L}_{n}=d g^{q^{n}}$, whence $d=\frac{\mathrm{L}_{n}}{g^{q^{2}}}$, which reduees to the form given by the plagiarist of Mr. Gompertz $\left(\frac{\mathrm{L}_{0}}{g}\right)$ on making $n=0$. This is a misstatement of fact, of which, whether intentional or accidental, I have just reason to complain. I regret to say that it is not the only instance of the kind which appears in the paper now under consideration.

I next say that the formula $10^{\frac{k^{2} a}{\lambda p}\left(1-p^{x}\right)}$ is defective, because it does not contain the factor $\mathrm{L}_{0}$; and I point out, by a reference to a table of mortality calculated and published by the plagiarist of Mr. Gompertz, that he in practice supplies the defect of his formula. It will be seen by any person who is at the trouble to refer to the table A.1. of Mr. Edmonds's Life Tables, that $\mathrm{L}_{12}=100,000$ and $\mathrm{L}_{22}=92865 \cdot 8$; whereas if " the 
superfluous quantity $\mathrm{L}_{0}$ " (here $\mathrm{L}_{12}$ ) is omitted from the formula, we should have $\mathrm{L}_{22}=.928658$. How far this can be properly described as reproducing " the identical figures given as obtained by the substitution of unity for $\mathrm{L}_{0}$ " (v. p. 341), I again leave the reader to decide.

The next point to which I drew attention was that the plagiarist of Mr. Gompertz had committed the serious error of calling $d$ a particular value of $y$. He confesses to this error (p. 338), saying that "in strictness" he should have said something quite different to what he did actually say. Having made an undeniable mistake, it is only proper to acknowledge it when pointed out. Why then does he, nine lines further down, retract that confession by speaking of "the pretended verbal error"? This appears to me at least a great want of candour; for the error is beyond doubt a real, not a pretended one, whether it is only "verbal" or something more. The plagiarist of Mr. Gompertz expresses surprise that while pointing out his errors, I have not noticed a "really serious error of Mr. De Morgan." The reason is easily given. I have no ambition to become a public censor. I have, as stated in my former letter, a definite object in viow in exposing the errors of the plagiarist of Mr. Gompertz. I expect to demonstrate by doing this, that his imputations on Mr. Gompertz, besides being unfounded, are without weight, as coming from a person whose acquaintance with the subject is imperfect. If Professor De Morgan had committed a really serious error, no similar reason existed why I should point it out, and no good object was to be gained thereby.

Further on, I show that the plagiarist of Mr. Gompertz has himself changed the sign of the quantity $c$, which he had asserted that Mr. Gompertz changed. The truth of my statement is not denied; but the plagiarist of Mr. Gompertz appears to have had this remark in view while writing the second paragraph on p. 337. He there says that Mr. Gompertz has changed the sign of the exponent of $g$. This is a phrase which is literally unmeaning. We have $g=10^{c}=10^{-\frac{k^{2} a}{\lambda q}}$, where it is obvious that the "exponent of $g$ " is unity;* and how its sign is changed by Mr. Gompertz, or can be changed at all, it is impossible to imagine. What the plagiarist of Mr. Gompertz apparently meant to state, was, that Mr. Gompertz committed an error in making the above supposition as to the values of $g$ and $c$, instead of taking $g=10^{c}=10^{+\frac{k^{2} \alpha}{\lambda \alpha}}$. When stated in this plain way, and cleared of the mist of verbiage in which it has been diligently involved by the plagiarist of Mr. Gompertz, the whole objection is obviously futile. Mr. Gompertz was clearly at liberty, without committing an error or introducing a "defect," to make whichever supposition he pleased as to the values of $g$ and $c$. The one supposition would have given him the formula, $\frac{d}{g^{q}}$, instead of that which he has actually employed, $d g^{q^{x}}$. The plagiarist of Mr. Gompertz considers the former of these formulæ to be preferable. Mr. Gompertz preferred the latter : and so, I believe, will all your readers who consider the point.

Here I would call attention to a curious inconsistency between the first and third paragraphs on p. 337. The first states that the equation

* It seems probable that the quantity $c$ is intended by this term, but $c$ is the common logarithm of $g$, not its exponent. 
$y=d g^{p^{x}}$ is defective because it has not introduced the quantity $\mathrm{L}_{0}$ by putting $\frac{\mathrm{L}_{0}}{g}$ for $d$; the third asserts that $\mathrm{L}_{0}$ ought not to have been introduced, and that the formula is defective because use has been made of $\mathrm{L}_{0}$ ! It is, of course, obviously impossible that both these charges can be true, and the slightest examination of Mr. Gompertz's process will satisfy the reader that it is not chargeable with the "defect" of introducing $\mathrm{L}_{0}$. I cannot leave this point without noticing that $\mathrm{L}_{0}$ is incorrectly introduced into Mr. Gompertz's process by his plagiarist; for, as I have already pointed out (p. 291), Mr. Gompertz takes $x$ throughout to denote the age measured from birth, so that the correct quantity to introduce is $\mathrm{L}_{n}$, and not $\mathrm{L}_{0}$.

The last of my remarks to which the plagiarist of Mr. Gompertz has attempted a reply, has reference to a misquotation by him of Mr. Gompertz's words. I will not occupy your space by again quoting the passage misquoted, but refer those who wish to verify what I state, to p. 293. The plagiarist of Mr. Gompertz has quoted a portion of a trypothetical sentence, which was not intended as a formal statement of the law of mortality, and argues on the strength of the misquoted passage, that Mr. Gompertz has committed an error, in not stating that his law of mortality does not prevail throughont the whole of life with the same constants. The truth being, that when Mr. Gompertz does state his law of mortality, he is very careful to limit it to a "long portion of life." I could have easily supposed that the misquotation was made through haste, but it is actually defended in the recent paper of the plagiarist of Mr. Gompertz! It is described as a simple omission of the "insignificant word" if! This is the first time I have ever heard the word if described as insignificant. The point will be made clearer by an example. Thus I may say, "If Mr. Edmonds has knowingly misrepresented facts in order to deprive Mr. Gompertz of the credit to which he is justly entitled, then he will not be correctly described by the term 'plagiarist,' bnt a far stronger term must be applied to him!" Suppose this passage to be quoted thus:- "Mr. Edmonds has knowingly misrepresented facts in order to deprive Mr. Gompertz of the credit to which he is justly entitled;" and we shall have an exact parallel to the misquotation with which I charge Mr. Edmonds. Perhaps this example may convince that gentleman that the little word "if" is not so "insignificant" as he has hitherto imagined. But it seems (p. 340) that "if" is used by Mr. Gompertz in the sense "let it be assumed." This I deny; but supposing it were, I cannot see that it would in the least affect the question.

The simple facts of the misquotation are these. Mr. Gompertz carefully limits the application of his hypothetical law of mortality to a "long portion of life." His plagiarist omits all reference to the passage in which this limitation is made- whether from design or oversight I will not pretend to saybut quotes part of a sentence in an altered form, as a proof that Mr.Gompertz has erroneously omitted to limit the application of his law. It is not true, as the plagiarist implies, that the only difference between the passage as written by Mr. Gompertz and quoted by him, consists in the presence or absence of the word "if". The reader will see, by comparing the passages (pp. 174, 293), that "if" is replaced by "that"; "were" is replaced by "are", and "lost" by "loses"; while in further illustration of the looseness with which the plagiarist of Mr. Gompertz has made the quotation, it may 
be mentioned that he wholly omits the significant word "remaining", as applied to the "power of resisting destruction" by Mr. Gompertz.

A similar looseness exists throughout the recent papers of the plagiarist of Mr. Gompertz. In one instance, I have to complain that my words are misquoted. I am represented (p. 339) to have said that "the process of integration had not commenced when the erroneous $(b)$ first appeared." On referring to p. 291 , it will be seen that my actual words are, " $b$ makes its appearance in step (2), while the integration is not performed till (3)." By the substitution, whether from design or carelessness, of the word com. meneed for the original one performed, a totally new complexion is given to the sentence, and the original meaning is obscured and perverted.

Again, it is stated (p. 338) that " Mr. Gompertz has recently presented to the Institute of Actuaries a corrected copy of his paper." The indefinite word recently is calculated to leave a false impression on the mind of the reader-whether designedly or not, I will not pretend to say. It would naturally be supposed, on reading the passage from which I have quoted, that the corrected copy of Mr. Gompertz's paper had been presented to the Institute of Actuaries, since attention has been drawn to that paper by the communication of Professor De Morgan, which appeared in the Assurance Magazine for July, 1860. So far from this being the case, I have ascertained that the copy was presented so long ago as F'ebruary, 1855. It is true that this may be termed recently in comparison with the date (1825) of the original paper; but this very circumstance renders the use of the ambiguous term more objectionable.

As another example of the same kind, I would refer to the description given by the plagiarist of Mr. Gompertz, of the problem proposed for solution. He says (p. 385; see also p. 338) that the object of Mr. Gompertz was "to find an expression for the number living at any age $(x)$ in terms of the annual moitality." This is incorrect. This was Mr. Edmonds's object, but was not Mr. Gompertz's. The object of the latter may be briefly expressed as follows:-The mortality (not the annual mortality) at any age $x$ being proportional to $q^{x}\left(\right.$ i.e. $\left.=a q^{x}\right)$, required a formula for the number living at the age $x$. Mr. Gompertz's formula $\left(d g q^{*}\right)$ gives the correct solution of his problem, and Mr. Edmonds's formula, corrected by the introduction of $\mathrm{L}_{0}$ (thus, $\mathrm{L}_{0} \cdot 10^{\frac{k^{2} a}{\overline{\lambda p}}\left(1-p^{\omega}\right)}$ ), gives the correct solution of his problem.

The plagiarist of Mr. Gompertz expresses his belief (p. 333) that that gentleman has never complained that any wrong has been done him by a failure of due acknowledgment of the priority of his discovery. Here I would direct attention to the gradual change of tone in the paragraph relating to this point. First it is "I do not believe," then "I have never heard," and finally "Mr. Gompertz himself, during the period of 28 years, remained insensible to the supposed wrong." Truly a very positive statement to base upon so slender a foundation of fact, or rather belief! With reference to this point, I happen to have beard from a gentleman, himself a Fellow of the Royal Society, that Mr. Gompertz has, upon one occasion at least, in the course of conversation at the Royal Society, some twenty-five years ago, expressed in emphatic language his belief that his theory had been adopted without proper acknowledgment. It is easy enough to understand that gentlemen who have been "in free personal communication" with both 
Mr. Gompertz and his plagiarist, and therefore, it is to be presumed, on friendly terms with both, would not make known a circumstance of this kind to the latter; and this consideration may suggest to that gentleman that it is not safe to assume that an event has not taken place because he has not heard of it.

The plagiarist of Mr. Gompertz states (p. 334) that his paper of Oct., 1860, "was written in self-defence (against an ontrageous attack of Mr. De Morgan)." It appears to me that that paper contained an outrageous and unprovoked attack upon Mr. Gompertz, and that the more recent paper of last July contains another "outrageous attack" upon the same gentleman.

Thus a very laboured effort is made (p. 335) to show that Mr. Gompertz has fallen into a serious error with regard to the nature of the quantity $a$ in bis formula $a q^{x}$ for the mortality at any age $x$. There is not the slightest foundation in fact for this charge, as I will now proceed to prove. It is by no means easy to perceive at first sight the precise meaning to be attached to the quantities $a$ and $a$ as employed by the plagiarist of Mr. Gompertz, in consequence of the obscurity of the language he has employed. I believe, however, that the following will be found to be a clear and faithful exposition of the distinction he means to draw. Adopting for the present his own letters, we have $\boldsymbol{a} p^{x}$ for the rate of mortality at the age $x$. The meaning of this quantity is best seen by the application that is made of it: thus the number dying in the small time $d x$, out of $\mathrm{L}_{x}$ alive, is stated to be $\mathrm{L}_{x} a p^{x} d x$. Whence we see that, in mathematical language, $\mathrm{L}_{x} a p^{x}$ is the limit of the ratio which the number dying in a small time bears to that time, when both are indefinitely diminished. If we represent the number alive at age $x$ by nnity, this ratio becomes $a p^{x}$, and at the age 0 it is simply a. Now in making a comparison with any actual table of mortality, we naturally take the annual mortality at the age considered. This will not be represented by $a, i . e$. if the rate of mortality as explained above is $a$ at the commencement of the year, and is supposed to remain constant throughout the year, the number who die in the year out of $\mathrm{L}_{0}$ persons living at the commencement will not be $a \mathrm{~L}_{0}$. In order to determine the annual mortality we must proceed as follows:-the number alive at the commencement of the year being $\mathrm{L}_{0}$, suppose the year divided into $\nu$ equal portions, then the number dying in the first small interval $\frac{1}{\nu}$ will be $\frac{\mathrm{L}_{0} \alpha}{\nu}$. Thus there remain alive $\mathrm{L}_{0}\left(1-\frac{a}{\nu}\right)$ persons, and of these $\mathrm{L}_{0} \frac{\alpha}{\nu}\left(1-\frac{\alpha}{\nu}\right)$ will die in the next interval $\frac{1}{\nu}$, leaving $\mathrm{L}_{0}\left(1-\frac{2 a}{\nu}+\frac{a^{2}}{\nu^{2}}\right)$ $=\mathrm{L}_{0}\left(1-\frac{a}{\nu}\right)^{2}$ alive at the end of the-second interval. Pursuing the same process, it is easily seen that the number surviving at the end of the year must be $\mathrm{L}_{0}\left(1-\frac{\alpha}{\nu}\right)^{\nu}$. Now pass to the limit by supposing $\nu$ indefinitely large, and this quantity becomes $\mathrm{L}_{0} e^{-\alpha}$. Thus the number dying in the year will be $\mathrm{L}_{0}\left(1-e^{-a}\right)$, whence the quantity $1-e^{-a}$ represents the annual mortality. 'The plagiarist of Mr. Gompertz supposes the annual mortality to be such that out of $1+a$ persons alive at the beginning of the year, $a$ die in the course of the year, so that the annual mortality is $\frac{a}{1+a}$. Thus 
then he gets $\frac{a}{1+a}=1-e^{-a}$, whence $e^{-a}=1-\frac{a}{1+a}=\frac{1}{1+a}$, and $1+a=e^{a} ;$ also $a=\log _{e}(1+a)$.

The only argument put forward in order to support the charge against Mr. Gompertz that he was ignorant of the real nature of the quantity $a$, is that he has made no statement of "any algebraical or arithmetical value of $a$ or $a . "$ It is difficult to attach any precise meaning whatever to these words; but the thing intended appears to be this :--Mr. Gompertz has not explained the precise meaning of his quantity $a$, nor given any numerical example from which that meaning might be inferred-therefore he was ignorant of its meaning! The truth is that for Mr. Gompertz's object of comparing the survivors at any age with his formula $d g^{x^{x}}$, it was not necessary to make any inquiry as to the nature of the quantity $a$. But this affords not the slightest ground for supposing be was ignorant of its nature.

It is true that there is no unqualified assertion made that $\mathrm{Mr}$. Gompertz is in error on this point. We read however (p. 336), that "the differential equation of $\mathrm{Mr}$. Gompertz is erroneous if he has used the finite decrement $(a)$ to represent the mortality;" see also p. 340. Now in reading this sentence, it must be borne in mind that the plagiarist of Mr. Gompertz looks on the little word if as an insignificant word, so that his meaning must be that there is very little doubt indeed, in fact none at all, that Mr. Gompertz was in error. We have seen that there is no foundation whatever for this assumption, and that $\mathrm{Mr}$. Gompertz in this, as in all the other points I have considered, is strictly accurate. Let us now turn and consider more closely the remarks of his plagiarist on this point, and there will remain no doubt that he has fallen into two very distinct and serious errors.

In the first place, he has taken to denote the annual mortality a quantity $a$ such that the number living at the commencement of the year is to the number living at its end as $1+a$ is to 1 . Instead of this, the correct assumption is to take $a$ so that the number entering on the year is to the number surviving it as 1 to $1-a$. This is a fundamental error, and one that was not to be expected from the veriest tyro in actuarial science. To put the point in another way:- the annual mortality at any age $x$ is found by comparing the finite decrement for one year with the number living at the beginning of the year; whereas the plagiarist of Mr. Gompertz has compared it with the number living at the end of the year! The practical result of this error will be, that supposing $a$ to be the mortality at the beginning of a year, the plagiarist of Mr. Gompertz makes the actual mortality of the year greater than $a$, instead of less as it obviously should be. To take the figures given by him in p. 335 , if $a=\cdot 0063643$, then will the actual mortality of the year be $1-e^{-a}$ or $\cdot 0063440$, instead of $\cdot 0063845$ as stated.

Again, in calculating the actual mortality of the year, the plagiarist of Mr. Gompertz supposes the rate of mortality constant throughout the year. This is contrary to the fundamental hypothesis, that the mortality at any age $x$, integral or fractional, is $a p^{x}$. The mortality varies throughout the year, and the actual annual mortality will be neither $e^{a}-1$ as the plagiarist of Mr. Gompertz has it, nor $1-e^{-a}$ as found by me above. The real annual mortality is found by a very simple process, for it is equal to $\frac{\mathrm{L}_{x}-\mathrm{L}_{x+1}}{\mathrm{~L}_{x}}=1-\frac{\mathrm{L}_{x+1}}{\mathrm{~L}_{x}}$. 
But

$$
\mathrm{L}_{x}=d g^{p^{x}}, \mathrm{~L}_{x+1}=d g^{p^{x+1}}
$$

whence

$$
\frac{\mathrm{L}_{x+1}}{\mathrm{~L}_{x}}=\frac{g^{p^{x+1}}}{g^{p^{x}}}=g^{p^{x+1}-p^{x}}=g^{(p-1) p^{x}} .
$$

Also $g=10^{\circ}=10^{-\frac{a k^{2}}{\lambda p}}$; so that the correct value of the annual mortality in terms of known quantities is

$$
1-g^{(p-1) p^{x}}=1-10^{-\frac{\alpha k^{2}(p-1)}{\lambda p} \cdot p^{x}}
$$

which becomes when $x=0,1-10^{-\frac{a k^{2}(p-1)}{\lambda p}}$.

Before leaving this point, I would call the attention of your readers to the circumstance that the plagiarist of Mr. Gompertz has termed $\alpha$ (p. 335) the most important quantity in the formula $d g q^{x}$. What! Is it more important than $q$, which is "part of the foundations of the universe"? ( $V$. p. 177.) We have here a remarkable instance of a complete revolution in opinion in the course of nine months. In October, 1860 , it was stated that $q$ is "distinguished from other but less important constants used"; in July, 1861, it appears that $a$ and not $q$ is the most important constant!

On the same page we read:- "Previous to forming the differential equation, it is essential that the nature of the quantity $(a)$, given to represent the proportional mortality for one year when the mortality is constant, should be determined." With regard to this, I simply remark that the success with which Mr. Gompertz has applied his formula to the examination of various tables of mortality, without previously examining into the nature of $a$, sufficiently shows that it is not essential that the nature of $a$ should be determined. Secondly, I would particularly draw attention to the fact that $a$ is not "given" by Mr. Gompertz "to represent the proportional mortality for one year when the mortality is constant." He nowhere throughout his paper speaks of the mortality being constant for one year; but on the contrary consistently supposes the mortality to vary at every instant of life; and he nowhere speaks of $a$ being the mortality for one year. His words are that "the intensity of his mortality at the age $x$ may be denoted by $a q^{x}$." In this instance, as in several others, Mr. Gompertz's words are wholly misrepresented. Before leaving this point, I may remark that it is quite impossible the annual mortality should be expressed by two different quantities (v. p. 335). If the one quantity correctly expresses the annual mortality, it is obvious the other cannot do so too. I have already shown that neither of the two quantities described by the plagiarist of $\mathrm{Mr}$. Gompertz correctly expresses the annual mortality.

Not only is Mr. Gompertz's accuracy called in question, but his truthfulness is also impeached. We are told (p. 330) that Mr. Gompertz has lent "his approbation to papers containing stalements which, from his superior knowledge of the facts, he could not, with any regard to truth, have uttered himself." Unfortunately, we are left to conjecture what those untrue statements are. For myself, I can find no statement, either in Professor De Morgan's paper or my own, to which that description will apply. It is therefore impossible to disprove this serious charge; but I feel not the slightest doubt, that all your readers will agree with me in considering that the plagiarist of $\mathrm{Mr}$. Gompertz has pursued an unwarrantable course, in recklessly making this grave charge without the least 
attempt to substantiate it. Similarly, we are told that "his advocates advance claims on his behalf, which Mr. Gompertz has never advanced himself." Here again, no attempt is made to point out these claims, and I am therefore only able to give a general denial to the assertion. I can discover no new claims put forward on behalf of Mr. Gompertz by Professor De Morgan and myself, and I do not believe that any such have been put forward. So, again, we are told there is only one instance of "concurrence of views" between Mr. Gompertz and his two advocates, "in the recently published papers of the three parties." It would have been more to the point if the plagiarist of Mr. Gompertz had given any example of discordance of views between "the three parties." Probably he has not done so, because he was unable to find any. With regard to the particular point which he has noticed as one of agreement, viz., the statement that he has given no proof of the truth of his supposed law of mortality, I have several times carefully read Mr. Gompertz's letter which is contained in the Assurance Magazine for April, 1861, and have failed to discover that he makes any statement of the kind at all. In fact, after carefully reviewing the whole of the remarks on p. 330, the conclusion appears unavoidable that they were written with far greater regard to effect than to truth.

A great deal has been said about the errors which appear in $\mathrm{Mr}$. Gompertz's process, as printed in the Philosophical Transactions. I bad hoped that I had satisfactorily shown that those errors are simply errors of the press, and that the process itself is free from any intrinsic error. In this view I am supported by the manuscript corrections in the copy of $\mathrm{Mr}$. Gompertz's paper belonging to the Institute of Actuaries, and by Mr. Gompertz's own remarks in the Assurance Magazine (p. 297). Even without such support, I submit that when a gentleman of undoubted mathematical ability starts with a correct equation $a \mathrm{~L}_{x} q^{x} \dot{x}=-\left(\mathrm{L}_{x}\right)$, and ends with a correct solution $\mathrm{L}_{x}=d g q^{a}$, it is only reasonable to suppose that he is aware of the correct intermediate steps, and that any errors which appear in the published process arise-not from ignorance or carelessness on the part of the anthor-but from a want of proper supervision of the press. On one point I venture to differ with Mr. Gompertz. He wishes for "a sufficiently clever mathematical superintendent of the press." On the contrary, I am of opinion that it is preferable to have a superintendent of the press who is ignorant of mathematics, but familiar with mathematical symbols. For it is clearly impossible to obtain one with sufficient mathematical knowledge to "restore" a demonstration such as Mr. Gompertz's published one; and a person of imperfect knowledge, who attempts to make conjectural emendations, is likely to introdace more new errors than he corrects. On such grounds I have been given to understand that women are often found better compositors of Latin and Greek works than men, because being quite ignorant of the language, they simply set up what is put in their hands, and do not introduce eriors by attempting to correct fancied mistakes. Thus the whole responsibility of correcting the press is left to the author. It appears from the remarks on pp. 338-9, that the plagiarist of Mr. Gompertz does not yet allow that the second $b$ is a printer's error. He has pat forward a conjecture ( $\mathrm{p}$ 339) to account for the introduction of $b$, which supposes a degree of ignorance or carelessness on the part of Mr. Gompertz, which is quite inconceivable on the part of a gentleman of such proved mathematical attainments. Mr. Gompertz is represented as having erro- 
neously supposed that because a constant was introduced by integration on one side of the equation, therefore another was required on the opposite side! This is wholly opposed to the fundamental notion of integration, by which one constant only is introduced; and it is clearly impossible to entertain the supposition for an instant. This theory has been put forward in apparent forgetfulness of a different explanation that was volunteered (pp. 181, 184) to account for the appearance of $b$. Both of these explanations cannot be correct, and I believe neither is.

I would ask the plagiarist of Mr. Gompertz how he accounts for the corrections made by Mr. Gompertz's authority in the copy of his paper belonging to the Institute of Actuaries-made, it should be remembered, before February, 1855? This at least shows that Mr. Gompertz at that date repudiated the letter $b$ as a misprint, and as forming no part of the correct process. When does his plagiarist suppose he became aware of the error? This error is exactly such a one as I should expect to see introduced by a compositor who knew something of algebra. The letter $b$ having been introduced in the previous step erroneously, and the equation $a \dot{x} q^{x}=-\frac{\dot{\mathrm{L}}_{x}}{\mathrm{~L}_{x}}$ having been written $a b q^{x}=-\frac{\dot{\mathrm{L}}_{x}}{\mathrm{~L}_{x}}$, such a compositor would naturally argue-- "the letter $b$ must have been forgotten by the author in "the next step. Instead of $a q^{x}$, which the MS. shows in the next step, we "should clearly have $a b q^{x}$, as in the previous one." It must be borne in mind that the plagiarist of Mr. Gompertz allows the introduction of $b$ in the former of these cases to be a genuine misprint.

In the same passage (p. 339) occurs a statement for which I am wholly unable to account:- "The equation, as corrected, is more defective, in form, at least, than was the equation intended to be corrected. . . . . The correction now made would leave no new constant on either side of the equation." The corrected equation in question will be found on p. 289 indicated by (3), and contains the new constant (d). I shall feel obliged if the reader will refer to this passage and verify my statement, and then endeavour to reconcile it with the one I have quoted above.

On the same page it is stated that I do " not call in question the truth of the substantial part of the statement" that " $b$ is introduced through an incorrect process of integration, and is superfluous, useless, and erroneous." I certainly intended to call in question the truth of this. I have stated and, I believe, proved, that Mr. Gompertz's process is not erroneons, and that $b$ is not a superfluous, useless, and erroneous constant, but is simply a misprint. It appears to me that I have thus, in a sufficiently plain manner, called in question the truth of the statement, not only of its form but of its substance.

Besides the imputations on Mr. Gompertz's accuracy, we have others on his language and style (p. 329) to which it is only desirable to refer in order to show the spirit which animates the remarks now under review. I should be glad to learn how it can affect the questions at issue, whether Mr. Gompertz's language is "homely" or "transcendental." Surely it must be a very weak case which needs the support of such an argument as is here implied!

In my former letter I showed the necessity of detailed evidence before admitting the truth of the supposed "true law of mortality." In consequence of this challenge apparently, we have now-set forth (p. 331) a short 
table comparing the mortality among the male population of England during 10 years according to observation and according to theory. On this $I$ would remark that the agreement of the two does not proceed in any part of the table beyond the first decimal place, so that we are still left in ignorance as to the materials from which the values of $p$ were computed to seven decimal places, and the logarithms to four decimal places. In addition to this, a large number of instances must be produced before it could be allowed that the law is commonly, much less universally, true. I would also ask whether the plagiarist of $\mathrm{Mr}$. Gompertz will assert that the example he has produced is not equally in favour of the new law of mortality as recently stated by Mr. Gompertz?

Besides the errors which I have already shown are chargeable to the plagiarist of Mr. Gompertz, his language in various passages renders it extremely probable that he has fallen into another serious error. He says (p. 328) that his law of mortality is such that if the annual mortality at age 25 were 1 per cent, and at 45 were 1.80 per cent, then the annual mortality at the intermediate ages would be found by interpolating the terms of a geometric progression. Again, on p. 329 , he says that "the annual rate of mortality increases in a geometric progression, of which the common ratio is $(p)$." Now, bearing in mind the distinction already pointed out, viz., that if $a p^{x}$ be the rate of mortality at the age $x$, then the annual mortality at that age will be $1-g^{(p-1) p^{x}}$, it is obvious that the annual rate of mortality does not increase in geometric progression; but on the contrary, the chance of living a year $\left(=g^{(p-1) p^{x}}\right)$ decreases in a geometric progression.

After all that has been already said, it is needless to comment at any length on the remarks contained in p. 330 and elsewhere, to the effect that $\mathrm{Mr}$. Gompertz's method of procedure, in comparing the numbers living at various ages with those given by his formula $d g^{q^{x}}$, is not so good as the method of comparing the mortality in successive decennial periods of age. This simply amounts to saying that Mr. Gompertz's method is inferior to that of his plagiarist. This is a point upon which difference of opinion may fairly exist. The plagiarist of $\mathrm{Mr}$. Gompertz should therefore have given it as his opinion, not asserted it as a fact, that the one method is preferable to the other. We must not omit to notice however the curious statement on p. 329 , that the formula $10^{\frac{l^{2} \alpha}{\lambda p}\left(1-p^{x}\right)}$ is " $d g^{p^{x}}$ corrected and reduced to its simplest terms." It might be thought that it would be allowed on all hands that the latter formula is far simpler than the former; but it seems that long continued admiration of the former has led its author to claim for it merits which it certainly does not possess.

In conclusion, I beg to state that I regret extremely the personal character which this controversy has taken, but it has been forced upon me. When general and unsupported charges of inaccuracy are preferred, such as those which I have already pointed out, and such as that preferred against myself on p. 340 , it becomes necessary to examine into the accuracy and knowledge of the person who makes them. If he is found to be a person free from error and accurate in his writings, his charges, although unsupported, will have weight with the world; but if on the other hand he should be found singularly inaccurate, then his charges will be disregarded and fall harmless to the ground, or recoil upon himself. Bearing these facts in mind, I have endeavoured to show the credit which I think should 
be attached to the charges preferred by Mr. Edmonds against Mr. Gompertz, and I must leave it now to the scientific public to pronounce their verdict.

I have the honour to be, Sir,

Your obedient servant,

25, Pall Mall,
September, 1861.

T. B. SPRAGUE.

ON THE TABLES OF DEFERRED ANNUITIES PUBLISHED BY THE NATIONAL DEBT OFFICE.

To the Editor of the Assurance Magazine.

Dear SIR,-Having had occasion to refer to the above-mentioned Tables, I have been surprised to find that they are not computed in the usual way, but apparently on some principle wholly different from it. I append instances in respect of single premiums (but the same remark applies to the annual ones), in which your readers will observe that the premiums charged by the Government are, for the most part, greatly in excess of those resulting from calculations made on the true principles. The publication of these discrepancies may possibly bring about some explanation of the reason of them; and I therefore have to beg the favour of your inserting this communication in your Journal; remaining-

Dear Sir,

Yours truly,

London, August, 1861.

J. W. STEPHENSON.

Deferred Annuities of Thirty Pounds-Males.

Single Preminms, returnable without Interest at any time prior to commencement of Annuity, pursuant to $16 \& 17$ Vict, cap. 45 .

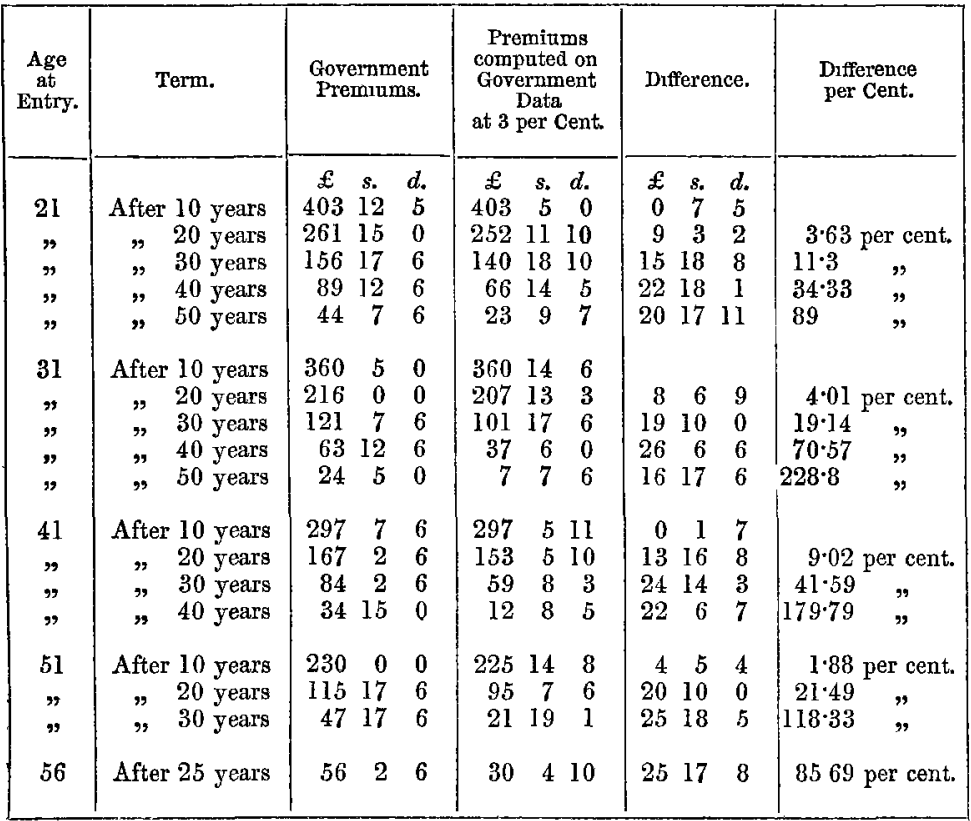

